\title{
Actos de disenso como urbanismo democratizador: el espacio político en Santiago de Chile
}

\author{
Atos de dissidência como urbanismo democratizante: o espaço político em Santiago \\ de Chile
}

Dissensual actions as democratizing urbanism: the political space in Santiago de Chile

José Francisco Vergara Perucich [a]

[a] Universidad Católica del Norte, Instituto de Economía Aplicada Regional (IDEAR), Departamento de Economía, Observatorio Regional de Desarrollo Humano (ORDHUM), Antofagasta, Región de Antofagasta, Chile

Cómo citar: Perucich, J. F. V. (2019). Actos de disenso como urbanismo democratizador: el espacio político en Santiago de Chile. urbe. Revista Brasileira de Gestão Urbana, 11, e20170195. https://doi.org/10.1590/2175-3369.011.001.A001

\section{Resumen}

El presente artículo busca avanzar en la teorización de un urbanismo del disenso. Ante el descrédito experimentado por la democracia representativa, parte de la ciudadanía ha escogido la calle y la marcha como mecanismos para expresar su malestar. Este fenómeno va en aumento y convierte a la ciudad en una caja de resonancia del malestar público. Utilizar el entorno urbano como medio para impugnar la democracia representativa construida sobre los consensos permite inferir el incipiente surgimiento de un urbanismo que también rompa con la tradición consensual de los procesos de producción urbana, hoy capturados por el mercado inmobiliario y la mirada tecnocrática. El artículo expone la potencialidad de desarrollar un urbanismo del disenso que contribuya a la democratización de la democracia. La investigación se localiza en el caso de Santiago de Chile, ciudad que desde el año 2006 ha contado con un aumento significativo en el número de marchas, a la vez que se ha visto reducida su participación política. Como resultado, el artículo reflexiona sobre la importancia de pensar un urbanismo que surja desde estas manifestaciones populares para dar forma a un espacio democrático producto de operaciones disensuales.

Palabras-clave: Disenso. Democracia. Urbanismo.

\section{Resumo}

Este artigo procura avançar na teorização de um urbanismo da dissidência. Confrontado com o descrédito experimentado pela democracia representativa, os cidadãos escolheram a rua e marcha como um meio para expressar a raiva. Esse fenômeno está aumentando e a cidade torna-se, então, um som que produz desconforto público. Usando o ambiente urbano como um meio para desafiar a democracia representativa construída em consenso, isso nos permite inferir o surgimento incipiente de um urbanismo que também rompe com a tradição dos processos de produção urbana consensual, hoje capturados pelo mercado imobiliário. Com base em evidências, o artigo expõe o potencial para desenvolver um urbanismo da dissidência e ajudar na democratização da democracia. A investigação centra-se sobre o caso de Santiago, uma cidade que desde 2006 teve um aumento significativo no número

JFVP es urbanista y doctor en desarrollo y planificación, e-mail: jose.vergara@ucn.cl 
de engrenagens, tendo, ao mesmo tempo, diminuído a participação política. Como resultado, o artigo reflete sobre a importância de pensar o urbanismo decorrente dessas manifestações populares para moldar um espaço democrático de operações de produto dissensual.

Palavras-chave: Dissidência. Democracia. Urbanismo.

\section{Abstract}

This article aims to advance in the theorization of the dissensual urbanism. The representative democracy is at the stake and people choose the street and the protest to demand changes. This phenomenon is increasing and the city has become an amplifier of people`s unrest. The use of urban spaces for contesting the democracy built upon consensus, and exposes the emergence of an urbanism that breaks the traditional approach of production of spaces, stripping these processes from the real estate market and claiming for new forms of urbanization. Based on evidence obtained by a fieldwork in Santiago de Chile, this article exposes the potentiality of a dissensual urbanism in order to democratize democracy. Given the exponential increase of the number of people marching to express their political posture, the street has stressed its function as political tool. On the other hand, the reduction of participation in traditional democratic instruments (like voting or trusting in representatives) exposes how this mode of consensual democracy is at the stake. Thus, new theories of urbanism are required for informing the imminent strengthening of dissensual urban spaces.

Keywords: Dissensus. Democracy. Urbanism.

\section{Introducción}

En Chile, el descrédito del Congreso Nacional y de los partidos políticos da cuenta de una importante crisis en el modelo democrático representativo. Según encuesta CEP 2016, en 2014 los chilenos evaluaban con un 5.1 de 10 la democracia chilena (es decir, reprobado). La confianza en las instituciones llegó a un 3\% para partidos políticos, 6\% para el Congreso Nacional, 7\% para Tribunales de Justicia, 12\% para empresas privadas y 15\% para el Gobierno (González, 2017). Mientras en Marzo de 1993 un 88\% se identificaba con algún partido político la cifra cae al 19\% en diciembre de 2016. Vale la pena considerar que entre 1990 y 2016 la sociedad Chilena se vio sumida en un trauma con el conflicto y el disenso heredado de los año de dictadura, trauma que después de 26 años se hizo cada vez menos sostenible ante las expectativas ciudadanas (Mayol Miranda \& Azócar Rosenkranz, 2011), que termina por agravarse con los escándalos de corrupción destapados a partir de los casos de Penta, Caval y SQM en 2015. El procesamiento del malestar busca respuestas en las instituciones y ante la ausencia de eficacia surge la protesta como mecanismo de expresión civil, cuya forma de buscar un remezón en la institucionalidad es mediante la ocupación del espacio público como canal de comunicación.

Lo cierto es que en medio del escenario descrito, el año 2011 involucró la aparición de las protestas y su legitimación, mucho más allá de lo esperable y predecible a comienzos del mismo año (Mayol Miranda \& Azócar Rosenkranz, 2011, p. 171).

Para Juan Pablo Paredes (2011) el diseño político-institucional de los gobiernos de la Concertación condujo hacia un déficit democrático caracterizado por una crisis del demos y la polis, expresado en una descomposición del tejido social y consecuente fragmentación expuesta en una disociación entre espacio político (congreso, gobierno, tecnócratas) y el espacio social (ciudades, hogares, barrios).

Desde 2011, la ciudad se ha convertido en un mecanismo para la expresión política, principalmente mediante marchas que buscan interrumpir las funciones habituales de la urbe para hacer que el malestar sea reconocido por la mayor cantidad de personas posibles. Estas alteraciones a la fluidez del movimiento en la ciudad, en la mayoría de las veces enfrenta respuestas represivas por parte de autoridades democráticas, exponiendo así la contradicción existente en la democracia representativa 
chilena: yo transfiero mi poder de decisión a un representante que cuando salgo a la calle para que me escuche utiliza la fuerza para reprimir mi postura político-espacial. Este artículo busca contribuir con una serie de reflexiones teóricas sobre un potencial urbanismo que represente a la ciudadanía que ve en el espacio público un canal político democrático, explorando la posibilidad de informar un urbanismo del disenso.

En la primera parte se presentan algunas razones detrás de la crisis en la democracia desde una mirada más global, a partir de conceptos para llegar a cuestionamientos que se hacen a la lógica consensuada que marcó la forma de hacer política entre 1990 y 2016 en Chile. Luego se formula una definición del urbanismo del disenso, originado en la impugnación de la institucionalidad democrática desde diversas miradas teórico-prácticas. Se argumenta sobre la importancia de la teorización de un urbanismo del disenso para contribuir desde las prácticas urbanas a democratizar la democracia.

Las conclusiones de este documento buscan puntualizar la importancia de avanzar hacia nuevas utopías urbanas, bajo la premisa de las utopías concretas elaboradas por Henri Lefebvre en 1970 (Lefebvre, 1970), para empujar nuevas teorías urbanas que avancen más allá del espacio como forma y logren aprovechar democráticamente la virtud del urbanismo como catalizador de procesos políticos.

\section{Democracia en una crisis planetaria}

Desde una aproximación conceptual, la democracia se enmarca en definiciones operativas, idealizadas y también visiones más críticas sobre su conformación. Quizás la más famosa definición idealizada sea de 1863, cuando Abraham Lincoln elaborase en el famoso discurso de Gettysburg: el gobierno del pueblo por el pueblo y para el pueblo. Desde una mirada operativa, el diccionario de Oxford define a la democracia como un sistema que incluye a las personas en las decisiones mediante la elección de representantes de sus voluntades, es decir, es la transferencia de poder mediante un sistema de votos. Detrás del pensamiento democrático en su origen se encuentra inmanente la defensa de la libertad, principio que puede tener diferentes interpretaciones. Para Alexis de Tocqueville (2003 [1835]), la democracia sería el balance entre libertad e igualdad, en busca del bien común y defendiendo los derechos individuales a la hora de construir una sociedad. Sin embargo, la teoría y la práctica democrática presentan históricas diferencias. Incluso Platón ubicaba a la democracia sólo como la tercera mejor manera de gobierno, detrás de la comunidad cretense y la oligarquía. Ante la innegable relación espacio-sociedad, donde la ciudad es un espacio socialmente producido y las relaciones sociales se reflejan en el espacio construido (Lefebvre, 1991), es esperable que las ciudades también sean un reflejo de las democracias que las produjeron. La relación entre ciudad y la democracia que la rige constituye una narrativa conjunta, compleja, entrecruzada y viva. Desentrañar esta relación requiere diversos esfuerzos teórico-prácticos.

La forma de definir la democracia en la actualidad enfrenta profundas contradicciones que se podrían explicar por sus propias falencias. Para Steven Bilakovics (2012), la conceptualización de la democracia no considera realmente a una ciudadanía participativa y aminora el poder popular en la formulación de la política pública, y cínicamente relativiza la influencia que los agentes económicos tienen sobre los procesos de tomas de decisión. Según Bilakovics, esta contradicción explica una de las causas de la desconfianza creciente de la ciudadanía hacia la democracia como sistema de gobierno. La evidencia obtenida por la Auditoría a la Democracia del PNUD (2014) indica que la confianza hacia las instituciones por parte de la ciudadanía puede terminar por mermar la legitimidad de reformas que son importantes para la nación y consecuentemente agudizar los cuestionamientos al sistema democrático que, según el mismo informe, requiere de una legitimación social. En este contexto crítico para el sistema actual, los argumentos de Bilakovics se conectan con los planteamientos de Chantal Mouffe (1999), cuando la politóloga belga llamaba a rediseñar la democracia abandonando la política de los consensos. En aquel entonces, Mouffe conceptualizó una significativa contradicción, explicando que la democracia estaba subyugada al acuerdo entre representantes democráticos, quienes basados en una deliberación anterior 
(una verdadera metodología del acuerdo), disolvían los límites entre diferentes posturas políticas, sin importar posturas ideológicas, actuando con extremo pragmatismo con el solo motivo de conseguir el desarrollo de proyectos tendientes a un supuesto progreso social bajo una matriz capitalista: crecimiento, empleo, inversión y acumulación de riqueza. Esto se sintetizaba en una izquierda y derecha política que se reunían en un centro, excluyendo de este proceso a las visiones de las personas a las cuales representaban. En esta reunión en el centro se realizaban un conjunto de debates previamente negociados que operaban sobre la búsqueda de neutralidad (o neutralización mutua), oculta bajo un manto de disputa aparente ante la ciudadanía. La diferencia entre argumentos entraba en una profunda agonía. Era el ocaso del debate como forma de hacer política, la instalación del consenso como única alternativa a un progreso que iba más lento que la misma sociedad. Sobre estos avances teóricos, el filósofo francés Jacques Ranciere (2010) establecerá la necesidad de avanzar hacia la producción de una democracia del disenso, en respuesta al enervante consenso. Para Ranciere, sin disenso no existirán transformaciones sociales significativas. Así, Ranciere afirma que los representantes de la voluntad popular deberían enfrentarse a la sociedad que los ha elegido, quienes les exigirán que cumplan el mandato que los ubicó como representantes. Ante la amenaza de una sociedad demandando su derecho a incidir en las decisiones políticas, la autoridad usará la violencia para defender el modelo democrático consensuado y acallar la voz que surge desde la calle reclamando a sus representantes que los representen. Quizás en este punto, radica la principal contradicción de la democracia consensual: la ciudadanía elige a los representantes y autoridades, pero cuando parte de la ciudadanía demanda ser escuchada, las mismas autoridades ejecutan medidas represivas contra la población.

En el caso particular de Chile, la crisis democrática es evidente. La Encuesta del Centro de Estudios Públicos de la Universidad Católica en Noviembre-Diciembre de 2016 determinó que sólo un 4\% confía en el congreso y en los partidos políticos. Esto se expresa en una baja participación electoral y por consiguiente en una inquietante deslegitimación del sistema democrático. Desde que se instauró el voto voluntario, las personas han ido reduciendo su participación en instancias democráticas tradicionales. Por ejemplo, en las elecciones municipales de 2016, solo un 35\% de la población mayor de 18 años fue a votar. Contrastando las definiciones de Bilakovics, Mouffe y Ranciere con estos datos, es posible inferir que la ciudadanía tiene una expectativa democrática incumplida, un anhelo sobre cómo se debería gobernar una nación y bajo qué parámetros. Siguiendo este supuesto, se puede inferir que dicha expectativa no se cumple y la crisis de las instituciones democráticas se podría explicar por una falta de representatividad, compuesto por un modelo de toma de decisión distante que descansa en representantes poco representativos, usando mecanismos y lenguajes que suenan ajenos al común de las personas. Los datos ayudan a confirmar estas aseveraciones. Por un lado, los partidos políticos que históricamente han sido los encargados de conducir las demandas de la población hoy cuentan solo con un 6\% de aprobación (CEP, 2017), mismo porcentaje de aprobación del Congreso Nacional. El excesivo uso de argumentos técnicos no se condice con la capacidad de comprensión de la ciudadanía, que según un el informe PIAAC de 2016, el 67\% de los adultos tienen bajo desempeño en comprensión lectora. Finalmente, la confianza interpersonal en Chile es crítica donde 9 de cada 10 Chilenos no confía en personas que no sean de su familia (OECD, 2016), lo que dificulta la empatía y la cohesión social en busca de objetivos comunes.

Esto es un problema de diseño político: la gobernanza de una nación opera bajo un cuerpo institucional insatisfactorio y distante para la ciudadanía, optando por una democracia consensual que es cada vez menos capaz de representar los intereses de la población. Sin ir más lejos y parafraseando a Erik Swyngedouw (2011), que las instituciones estatales repriman a la ciudadanía cuando se producen manifestaciones quiere decir que la autoridad no comprende lo que significa democracia en el amplio sentido de la palabra. Ante la eventual presencia de un modelo democrático fallido, bien puede resultar deseable la exploración de mecanismos para la profundización democrática.

El geógrafo Mark Purcell (Purcell, 2013) detectó el vacío existente entre la idealización de la democracia y la realidad de cómo ésta funciona en la práctica. La concentración del poder de toma de decisiones en unos pocos miembros de la nación que persiguen intereses particulares interfiere con el 
correcto desarrollo de gobiernos democráticos, lo que a su vez conduce a una producción democrática viciada, espuria, por ende, anti-democrática. Para Purcell, la resignificación democrática podría venir de la mano de la implementación de lo que Henri Lefebvre en 1968 llamó el derecho a la ciudad (Lefebvre, 1968). El derecho a la ciudad es una agenda de lucha, un objetivo político basado en la espacialización de las disputas por la democratización de la democracia, rediseñando las barreras institucionales que interfieren en el trayecto para su realización, representándose en la vida cotidiana y en las ciudades. Así es como a través de los espacios públicos de la ciudad, lo común, la democracia socializada busca su lugar y encuentra caminos para expresarse, para levantar su grito del disenso. En el espacio público ocurren significativos actos impugnatorios de un modelo político bajo cuestionamiento, y es mediante la crítica a la institucionalidad y sus autoridades que las políticas de lo público debiesen abandonar la lógica represiva y embarcarse en mecanismos disensuales, espacializados, representativos y legitimados socialmente.

\section{La democracia del disenso como expresión espacial significativa}

Mientras la ciudad está viva y florece, al menos en algunos espacios, la polis -el sitio donde ocurre el encuentro político y la negociación democrática del espacio- donde ocurren los disensos y los desacuerdos, tanto como el lugar donde la subjetivación política surge, es presentada; literalmente tomando su lugar, pero se ve moribunda. En otras palabras, la polis como espacio político está en retirada mientras el espacio social esta incrementalmente colonizado y suturado por políticas tecno-administrativas del consenso (Swyngedouw, 2011, p. 11).

Para la mirada de Erik Swyngedouw (2011) existen dos espacios políticos en la ciudad, uno moribundo compuesto por la polis, o el espacio tradicional del desarrollo de los encuentros democráticos tradicionales (los congresos, grandes explanadas, edificios gubernamentales) y el espacio social, aquellos lugares donde espontáneamente surgen expresiones de una política de lo otro, del disenso, caracterizada por ser provocativa y contestataria. Mientras que el desprestigio del sistema democrático tradicional que se originaba en la búsqueda colectiva de poder podría ser una de las causas del creciente individualismo (Hendriks, 2010), las consecuencias son la evidente falta de interés por la vida política tradicional, la pérdida de confianza en el voto como mecanismo de poder y la desesperanza ante la habilidad del político profesional en eludir los desacuerdos con sus pares (Mouffe, 1999). No obstante, la voluntad de progreso y necesidad de manifestar deseos de justicia social no necesariamente ha desaparecido, más bien, podría haber elegido nuevos caminos de expresión. El voto ya no se entiende como único mecanismo para decidir en democracia. Así, la ciudad se expone como una alternativa en donde lo colectivo puede representarse usando otras formas de ejercer el poder democráticamente. La auto-representación individual de un deseo en el amparo de un colectivo que se une en lo urbano para ejercer poder se refuerza como hecho político. Si bien las huelgas, protestas y marchas no son nuevas, el escenario actual de descrédito de la política y altos niveles de abstención electoral (en Chile el 59\% no salió a votar en 2013 y un 53\% en 2017) ponen en relevancia que, quizás, la democracia como ejercicio decisional avanza hacia sistemas más capaces de reconocer en la manifestación urbana popular una expresión válida para la demanda de políticas públicas.

El espacio público es virtuoso para estas expresiones gracias a su flexibilidad, se puede transformar desde un mero receptor de eventos para operar como una urna de votación a escala metropolitana, configurando un nuevo símbolo del poder democrático ciudadano en ejercicio, la democracia se independiza de la institucionalidad electoral central y un poder democrático surgiendo desde las calles pasa de ser una protesta a un evento transformador de políticas públicas. Para Michael Hardt y Antonio Negri (Hardt \& Negri, 2011), la democracia que conocemos en el mundo occidental avanza hacia su obsolescencia y los movimientos de protesta pueden y deben convertirse en un genuino proceso democrático constitutivo, compuesto por mecanismos deliberativos de asambleas y procesos de decisión participativos, validando también los aportes desde las redes sociales hacia la generación de 
estructuras decisionales más horizontales. El gran desafío, no obstante, está en cambiar de escala, logrando que una protesta en un lugar particular de la ciudad pueda ayudar a configurar un proceso decisional a escala urbana.

Ahora bien, ¿Existe una verdadera capacidad competitiva entre la asistencia a protestas y el ejercicio del voto como mecanismo democrático? Si bien esta relación puede merecer mayor atención metodológica, una primera exploración indica que al menos la protesta se sitúa con una fuerza política significativa en ciertos territorios. Como se indica en el Figura 1, la brecha entre cantidad de asistentes a marchas y votantes en elecciones presidenciales para la Región Metropolitana se ha ido acortando desde el año 2003, con la Marcha por las Víctimas de la Dictadura hasta la Marcha de No+AFP en 2017 (Tabla 1). Si bien la cantidad de personas que marchan se componen también por no votantes (menores de 18 años) se observa un fuerte aumento de las convocatorias. Todavía la cantidad de votantes cuadruplica la cantidad de asistentes a las marchas observadas, no obstante, mientras la política y la participación electoral va en declive, la participación en marchas va en aumento.

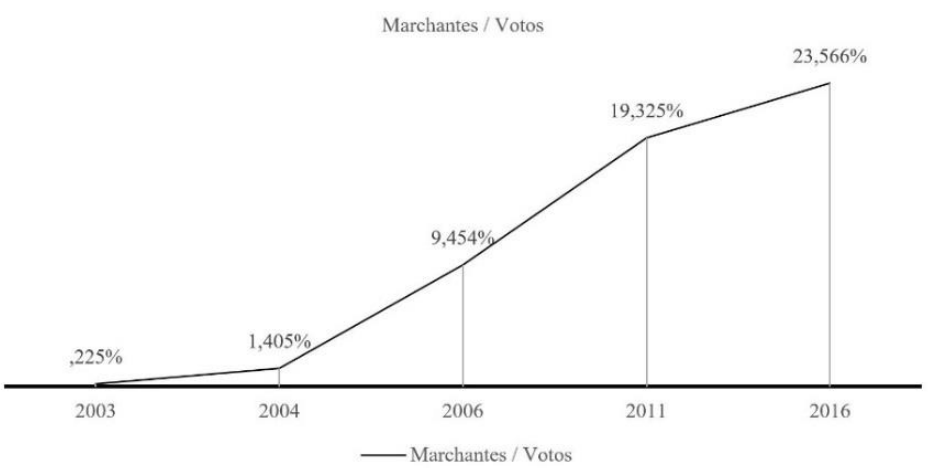

Figura 1 - Relación entre asistentes a marchas emblemáticas por período presidencial y votantes en elección presidencial.

Fuente: Autor en base a datos del SERVEL y archivos de periódico El Mercurio.

Tabla 1 - Relación entre asistentes a marchas emblemáticas por período presidencial y votantes en elección presidencial

\begin{tabular}{|c|c|c|c|}
\hline Evento político & Participantes & Marchas/Votantes \% & Año \\
\hline \multirow[t]{2}{*}{ Marcha Victimas Dictadura (14-09-2003) } & 6.000 & & \\
\hline & & 0,22 & 2003 \\
\hline Votos Segunda Vuelta Presidencial RM 2006 & 2.668 .607 & & \\
\hline \multirow[t]{2}{*}{ Marcha Contra George BUSH y la APEC (19-11-2004) } & 37.500 & & \\
\hline & & 1,41 & 2004 \\
\hline Votos Segunda Vuelta Presidencial RM 2006 & 2.668 .607 & & \\
\hline \multirow[t]{2}{*}{ Marcha de los Pinguinos (30-05-2006) } & 250.000 & & \\
\hline & & 9,45 & 2006 \\
\hline Votos Segunda Vuelta Presidencial RM 2009 & 2.644 .445 & & \\
\hline \multirow[t]{2}{*}{ Marcha de los Remolinos (21-08-2011) } & 425.000 & & \\
\hline & & 19,32 & 2011 \\
\hline Votos Segunda Vuelta Presidencial RM 2013 & 2.199 .250 & & \\
\hline \multirow[t]{2}{*}{ Marcha No+AFP (26-03-2017) } & 387.500 & & \\
\hline & & 23,57 & 2016 \\
\hline Votos Emitidos Municipales RM 2016 & 1.644 .318 & & \\
\hline
\end{tabular}

Fuente: Autor en base a datos del SERVEL. 
El espacio público, así, no es solo un lugar de encuentro de las personas sino un lugar donde se organizan $\mathrm{y}$, en base a la generación de un poder popular, son capaces de impugnar diferentes decisiones tomadas por instituciones democráticas. En la actualidad, es la propia democracia la que se ve impugnada en el espacio público. Tal como lo plantea Deyan Sudjic (2006), a diferencia de la ciencia y la tecnología que por convención intentan presentarse como disciplinas ajenas a connotaciones ideológicas, las disciplinas relacionadas a la producción de la ciudad son herramientas prácticas basadas en crear una materialidad especifica, pero también son lenguajes expresivos, capaces de crear mensajes políticamente cargados. Si una sociedad pretende construirse en base a valores democráticos, la ciudad será la plataforma, la representación y uno de los principales mecanismos de realización de ese proyecto social. Ignorar la importancia para la democracia que tiene la definición colectiva de la ciudad, es otra contradicción democrática que de momento se encuentra devaluada en relación a los escándalos de corrupción, pensiones, la segregación en la educación y los problemas medioambientales. Mientras la sociedad se organiza para usar a la ciudad como amplificador de demandas colectivas, la misma ciudad espera, ansiosa, que llegue su turno para que la ciudadanía reclame su total democratización a través de su reconfiguración.

Según David Harvey (2012), el espacio público ha sido frecuentemente transformado gracias a acciones sociales colectivas, en busca de aumentar los accesos a los beneficios de la vida urbana, buscando cambiar el modo en que la ciudad se ofrece ante sus ciudadanos. ¿Puede la ciudad ser un catalizador de procesos democratizadores? Esta pregunta ya era planteada por Henri Lefebvre en 1970. En su obra La revolution urbaine, Lefebvre puso en valor la capacidad de catalizar transformaciones sociales mediante acciones sobre las maneras de hacer ciudad, las cuales requerían de un compromiso real de los urbanistas, ausentes de las disputas políticas y muchas veces pasivos ante las consecuencias sociales de sus decisiones (Lefebvre, 2003 [1970]). Ahora bien, una participación más activa de los urbanistas en la democratización del espacio tendría que verse reflejado en algo más que una declaración de principios, sino en mecanismos efectivos de transformación urbana. El espacio público se ha transformado en un nicho de actores sociales empoderados con la capacidad de canalizar malestar y conducir un mandato popular por exigir transformaciones específicas a los sistemas que rigen la sociedad. En el caso de Santiago, las marchas del año 2011 levantaron a líderes políticos que se empoderaron desde el espacio público para transformarse en líderes de la democracia representativa. Ejemplos visibles son los casos de los líderes estudiantiles que hoy son diputados: Camila Vallejo, Karol Cariola, Giorgio Jackson y Gabriel Boric. Sin embargo, la bandera de estos actores fue la educación, mientras la ciudad espera una vocería a nivel nacional. Movimientos como UKAMAU, ANDHA Chile o el Movimiento de Pobladores en Lucha tiene vocación local y de transformación socio-espacial inmediata. Son potenciales semillas para una transformación de la ciudad en su totalidad, pero carecen del poder político (aún) para cambiar desde la escala barrial a la escala metropolitana.

\section{Diseñando una ciudad democrática}

El año 1983, el urbanista Alfredo Rodríguez plantearía una serie de lineamientos para lo que podría ser una futura ciudad democrática en Chile. En plena dictadura, las ideas de Rodríguez entonces sonarían a utópicas y principalmente representarían una época de profunda frustración ante los procesos de neoliberalización que se estaba sometiendo al aparato público de planificación urbana y las formas en que se estaba vejando a los hogares de escasos recursos a favor de un supuesto progreso impulsado bajo la ideológica mirada del libre mercado. Mientras en Chile la dictadura fundaba el urbanismo neoliberal a nivel mundial, los especialistas comenzarán a pensar alternativas para subsanar los potenciales efectos que estas transformaciones tendrían en la sociedad.

Un planteamiento que limite la propuesta de la democracia -al nivel de la ciudad- a la elección pública, secreta, universal de las autoridades urbanas, es un planteamiento restringido, segmentado. Es necesario incorporar al debate de la democracia en la ciudad la posibilidad de 
nuevas formas de generar y apropiar el espacio urbano rescatando el valor de uso (Rodríguez, 1983, p. 47).

La ciudad chilena tiene un pie forzado para la democratización del urbanismo, caracterizado por la herencia de la dictadura en relación al desmantelamiento del aparato público de planificación (Valencia, 2006) que le entrega toda la responsabilidad del desarrollo urbano y de las decisiones a la mano invisible del mercado. Para Marco Valencia (2006), el aparato público de planificación urbana se sometió a un "ataque ideológico" (Valencia, 2006, p. 13) materializado en políticas neoliberales, reduciendo la importancia del estado en materia de buscar el bien común. Al respecto, Miguel Lawner reflexiona sobre los cambios en los modos de hacer ciudad en Chile:

Todo eso se cambió entregando a la iniciativa privada toda la responsabilidad, tanto en el ámbito del desarrollo urbano como la vivienda. No hay ninguna posibilidad de que eso vele por el bien común de la comunidad. Las catástrofes en nuestras ciudades son demostrativas de eso (Mora, 2013).

Precisamente, la reflexión de una ciudad democrática planteada por Alfredo Rodriguez, buscaba rescatar y mejorar las experiencias de planificación urbana previamente concebidas en Chile. Em síntesis, Rodríguez expone cuatro dimensiones principales para comprender de qué manera se materializaría esta ciudad, los cuales se pueden interpretar de la siguiente manera:

Una ciudad de ciudadanos: fortaleciendo a los municipios, ampliando sus ingresos fortaleciendo el rol de articular la sociedad civil con el estado, vinculando políticamente a los ciudadanos con sus demandas y dándoles la posibilidad de realizar transformaciones significativas a su entorno urbano.

Una ciudad que acoge: basada en el acceso a la vivienda junto a la creación de oportunidades de trabajo que no implicasen largos desplazamientos en la ciudad. Para esto, Rodríguez expone la importancia de asegurar el derecho a la vivienda ya sea propia, alquilada o transitoria, insertando estas viviendas en circuitos de equipamiento público y de espacios que construyan posibilidades de una vida de barrio rica.

Una ciudad hecha por todos: clamando a la participación ciudadana de manera vinculante, interviniendo activamente en la creación, gestión y apropiación de los lugares en donde habitan los ciudadanos, yendo más allá de decir lo que se necesita, sino actuando y transformando el espacio para adecuarlo a las necesidades de las personas.

Una ciudad para vivir: "Una ciudad democrática destierra el miedo" (Rodríguez, 1983, p. 51). La represión desaparece y el orden de la vida urbana se configura de acuerdo a la voluntad colectiva, a lo que los ciudadanos comprenden como orden. También debe buscarse eliminar el miedo a las inseguridades como la cesantía, la inestabilidad laboral, o el miedo al otro.

Las propuestas de Rodríguez, en algunos casos, aún suenan lejanas a la realidad actual pero no carecen de sentido común ante una serie de problemáticas sociales que tienen una directa vinculación con estos principios antes mencionados. "Una ciudad hecha por todos es una ciudad cambiante, con un orden difícil que se construye día a día" (Rodríguez, 1983, p. 50). Esta ciudad aún no se ha materializado en Santiago, no obstante, ya han comenzado a hacerse más evidentes diversos fenómenos de resistencia contra la desregulación del suelo, de la laxitud de los instrumentos de planificación territorial y de la despolitización del espacio. Los urbanistas pareciera que comienzan a despertar, al fin, la atención de la ciudadanía y la preocupación por la importancia que tiene la ciudad para uno de los principios que históricamente han motivado a la clase trabajadora, el vivir bien. Lo cierto es que en la actualidad persiste una desconexión entre sociedad civil y producción urbana.

Para Miguel Lawner (Mora, 2013), esto debe cambiar, principalmente porque en materia de ciudad, actores clave como algunos inversores del mercado inmobiliario han terminado por socavar su propio prestigio en busca de renta, logrando a su vez desatar una serie de reacciones ciudadanas contra lo que estas empresas representan.

Ahí hay dos caminos. 0 lo haces como está ocurriendo, que llega una inmobiliaria, elige terrenos próximos a un punto estratégico, ofrece cualquier cantidad de dinero seductor a estas familias, 
levanta una torre de treinta pisos y arruina el barrio. 0 lo haces sobre la base de organizar a la gente, discutir cómo podemos renovar en beneficio y no en perjuicio de la población. Eso es un desafío maravilloso (Mora, 2013).

Bajo esta perspectiva y ante el régimen del urbanismo neoliberal, pareciera ser que los urbanistas tienen mucho que aportar a la redefinición democrática. La ciudad puede ser un campo de la política sobre el cual ejecutar mecanismos tendientes a fomentar la democracia del disenso. La búsqueda de lo que podemos llamar un urbanismo del disenso o la democratización de la ciudad, se puede también circunscribir en la disputa necesaria por el derecho a la ciudad de Lefebvre.

La transformación del principio del derecho a la ciudad en una estrategia urbanística, ha sido fruto de investigaciones diversas. Mustafa Dikeç y Liette Gilbert (Dikeç \& Gilbert, 2002, p. 73-74) han planteado que para desarrollar una democratización de la ciudad que formalice los postulados del derecho a la ciudad, se pueden elaborar estrategias que podrían traducirse en las siguientes acciones políticas:

- Cambiar las dinámicas estructurales que producen los espacios, pasando de la lógica de libremercado a transformaciones desarrolladas por las personas, redistribuyendo así el poder de dar forma a la ciudad, desde una minoría rentista a una mayoría en necesidad de vida urbana;

- Ampliando los alcances del derecho a la ciudad, facilitando el desarrollo de transformaciones en el espacio que vayan dando forma a una nueva etapa de la democracia, en la que la ciudad representa un proceso de toma de decisiones colectivas;

- Una nueva ética social. Quizás el más difícil de los postulados de Dikeç y Gilbert dado el importante enraizamiento del comportamiento neoliberal en la cotidianeidad de los chilenos. En lo concreto, se debería fomentar el hábito de vivir colectivamente a partir de un urbanismo capaz de catalizar estos comportamientos invitando a todos los actores sociales a dar forma al espacio urbano.

Las estrategias de Dikeç y Gilbert podrían leerse como una continuación de los postulados de Rodríguez y una propuesta de materialización del derecho a la ciudad en el contexto contemporáneo. Para alcanzar estos objetivos, entonces, se necesitaría fomentar la importancia del beneficio mutuo, de la cooperación entre los grupos organizados a favor de arbitrar la toma de decisiones teniendo como principal mecanismo la democracia para generar el discernimiento (Friedmann, 2010). Así, el urbanismo podrá despojarse de su máscara capitalista (Lefebvre, 2003 [1970]) y funcionar en base a las realidades contextuales, siendo una respuesta a necesidades y deseos ciudadanos, creando hechos materiales concretos, aportando desde la capacidad de comprender los conceptos de escala de intervención y estrategia de acción, rompiendo así con la interpretación de la arquitectura como un commodity y reforzando el sentido social del espacio (Boano et al., 2013).

Derivado del reto político, las políticas de ciudad deben buscar empoderar a la comunidad ciudadana, organizarla y proveerla de medios eficaces para participar y decidir sobre la ciudad que acoge sus vidas y proyectos (Correa Montoya, 2012, p. 6).

En la construcción de una democracia nueva, urbanística, las estrategias que pueden surgir desde el derecho a la ciudad podrían llegar a conducir transformaciones significativas que beneficien a toda la población.

\section{Conclusiones}

En la actualidad, existe una creciente participación de la ciudadanía en marchas como mecanismo de expresión de voluntades ante una democracia alicaída, cuestionada y debilitada por representantes que representan cada vez menos a quienes los eligieron. Este creciente fenómeno expone la importancia que ha tomado la ciudad en representar los intereses de las personas y como altavoz para manifestarse colectivamente a favor de ciertas iniciativas o en contra de otras. La ciudad, en su espacio público, se ha convertido en una urna de votación mientras la marcha actúa como el mandato popular que expresa su 
opinión y canaliza el descontento o las búsquedas de otros proyectos sociales. El consenso ha terminado por debilitar la democracia representativa y ha sido el disenso expresado en el espacio público el sistema elegido -quizás inconscientemente- por la ciudadanía para formular democráticamente sus demandas. La marcha, entonces, se constituye como el incipiente detonante de lo que he intentado teorizar como urbanismo del disenso.

Sin embargo, la marcha es efímera y la ciudad no logra resignificarse con eventos transitorios. La fuerza rutinaria del neoliberalismo tiende a volver las cosas a su cauce normal. La democratización de la ciudad debería superar la mera ocupación temporal de los espacios, avanzando hacia transformaciones estructurales en las formas en que el poder opera sobre la ciudad. Al fin y al cabo, la marcha es una significativa expresión de poder pero pronto desaparece y la ciudad vuelve a lo que se llama normalidad: el capital controla la ciudad, mientras el estado la ordena para optimizar los flujos del capital. Es aquí donde el urbanismo del disenso puede aportar más a la democratización de la democracia, a partir de las transformaciones en el espacio, usando como principio la ruptura de los límites entre lo público y lo privado a favor del bien común, impugnando las instancias materiales (espaciales) en que la privatización termina por expoliar a la ciudadanía, socavando derechos elementales. Al respecto, como reflexión propositiva, parece importante promover ciertas ideas provocativas que levanten discusiones acaloradas sobre una ciudad futura que sea radicalmente diferente. Por ejemplo, pensar la configuración de una ciudad sin fines de lucro. De seguro esta propuesta despertaría un conjunto de reacciones encontradas y opiniones divergentes sobre la viabilidad/conveniencia de pensar una ciudad sin fines de lucro, iniciando debates propositivos, radicales, que dialécticamente permitan generar progresos en el campo disciplinar del urbanismo. ¿Se puede hacer una ciudad sin fin de lucro? ¿Cómo se organiza? ¿Quién la diseña? ¿Cómo un urbanismo del disenso sobrevive a sus propias contradicciones metodológicas? ¿Cómo un urbanismo del disenso puede generar en un ambiente de paz social? Preguntas que rompen con los modelos consensuados de urbanismo que buscan fortalecer al capital y proveer de soluciones pasajeras a los más desposeídos. En una búsqueda por un urbanismo del disenso, plantear una ciudad sin fines de lucro en un contexto neoliberal parece ser una interesante provocación que cambia el escenario de impugnación desde la calle a una teorización de estrategias urbanísticas del disenso hacia transformaciones en los modos de hacer ciudad.

El urbanismo del disenso, en la práctica, se podría comenzar a perfilar como una herramienta dialéctica de análisis urbano que busca provocar en torno a lo que Henri Lefebvre llama las utopías concretas, aquellas ideas sugerentes sobre el futuro de la sociedad que se ven lejanas pero que con suficiente investigación socio-espacial pueden demostrarse que son alcanzables. El neoliberalismo es un ejemplo de utopía concreta: quizás en los años cuarenta, cuando se daban las primeras reuniones de la Mont Pelerin Society, no muchos pensaron que 40 años después el estado quedaría reducido a su mínima expresión para privilegiar la organización de la sociedad en torno al libre-mercado. Si bien los miembros de la Mont Pelerin Society visualizaban este hecho como algo distante, sí lo creían realizable, al nivel que hasta el día de hoy muchos de quienes heredamos este modelo buscamos maneras para deshacernos de él y aún no podemos. Más aún, en el camino nos hemos olvidado de elaborar nuestras utopías concretas propias, y en eso abandonamos nuestras propias ideas por las cuales luchar. Por ejemplo: ¿Qué viene después del neoliberalismo? ¿Cómo es ese futuro? El urbanismo del disenso podría sustentarse en la utopía concreta como mecanismo de progreso e invitación a la contestación, a la diferencia, a la dialéctica como medio creativo para revalorar la democracia y darle una nueva definición, así como también imaginar otros futuros para una sociedad democrática.

\section{Referencias}

Bilakovics, S. (2012). Democracy without politics. Cambridge: Harvard University Press. http://dx.doi.org/10.4159/harvard.9780674062931. 
Boano, C., Hunter, W., \& Newton, C. (2013). Contested urbanism in Dharavi. Writings and projects for the resilient city. London: Development Planning Unit, University College London.

Centro de Estudios Públicos - CEP. (2017). Encuesta Nacional de Opinión Pública, Noviembre-Diciembre 2016. Providencia: Centro de Estudios Públicos. Recuperado el 10 de enero de 2017, de https://www.cepchile.cl/estudio-nacional-de-opinion-publica-noviembre-diciembre-2016/cep/2017-0105/083311.html

Correa Montoya, L. (2012). Políticas de ciudad: planear la ciudad para reivindicar la dimensión humana. Polis (Santiago), 11(31), 103-123. http://dx.doi.org/10.4067/S0718-65682012000100006.

De Tocqueville, A. (2003 [1835]). Democracy in america (Vol. 10). Washington: Regnery Publishing.

Dikeç, M., \& Gilbert, L. (2002). Right to the city: homage or a new societal ethics? Capitalism, Nature, Socialism, 13(2), 58-74. http://dx.doi.org/10.1080/10455750208565479.

Friedmann, J. (2010). Place and place-making in cities: a global perspective. Planning Theory \& Practice, 11(2), 149165.

González, R. (Coord.) (2017). ¿Malestar en Chile?. Santiago: Centro de Estudios Públicos.

Hardt, M., \& Negri, A. (2011). The fight for 'real democracy'at the heart of Occupy Wall Street. Foreign Affairs, 11, 301-320.

Harvey, D. (2012). Rebel cities: from the right to the city to the urban revolution. London: Verso Books.

Hendriks, F. (2010). Vital democracy: a theory of democracy in action. Oxford: Oxford University Press. http://dx.doi.org/10.1093/acprof:oso/9780199572786.001.0001.

Lefebvre, H. (1968). Le droit à la ville. Paris: Anthropos.

Lefebvre, H. (1970). La révolution urbaine. Paris: Gallimard.

Lefebvre, H. (1991). The production of the space (D. Nicholson-Smith, trans.). Oxford: Blackwell Publishing.

Lefebvre, H. (2003 [1970]). The urban revolution. Minneapolis: University of Minnesota Press.

Mayol Miranda, A., \& Azócar Rosenkranz, C. (2011). Politización del malestar, movilización social y transformación ideológica: el caso “Chile 2011”. Polis (Santiago), 10(30), 163-184. http://dx.doi.org/10.4067/S071865682011000300008.

Mora, P. (2013). Entrevista a Miguel Lawner, el arquitecto de la UP. Plataforma Arquitectura. Recuperado el 18 de mayo de 2017, de http://www.plataformaarquitectura.cl/cl/02-291787/entrevista-a-miguel-lawner-elarquitecto-de-la-up

Mouffe, C. (1999). Deliberative democracy or agonistic pluralism? (Vol. 72, pp. 745-758, Political Science Series). Vienna: Institute for Advanced Studies.

Organisation for Economic Co-operation and Development - OECD. (2016). Financing democracy-funding of political parties and election campaigns and the risk of policy capture. Paris: OECD Publishing.

Paredes, J. P. (2011). Ciudadanía, participación y democracia. Polis, 28, 1-23.

Programa de las Naciones Unidas para el Desarrollo - PNUD. (2014). Auditoría a la Democracia. Más y mejor democracia para un Chile inclusivo. Santiago: PNUD.

Purcell, M. (2013). Seeking democracy (Vol. 13, pp. 2013). Society and Space-Environment and Planning. Recuperado el 18 de mayo de 2017, de http://societyandspace.com/material/discussion-forum/forumonturkey/purcell/

Ranciere, J. (2010). Dissensus: on politics and aesthetics. Londres: Bloomsbury Publishing.

Rodríguez, A. (1983). Por una ciudad democrática. Santiago de Chile: Ediciones Sur. 
Sudjic, D. (2006). The edifice complex: how the rich and powerful--and their architects--shape the world. London: Penguin.

Swyngedouw, E. (2011). Designing the post-political city and the insurgent polis (Vol. 10, Civic City Cahier). London: Bedford Press.

Valencia, M. (2006). La Ciudad de Libre Mercado: neoliberalismo y transformaciones del espacio urbano metropolitano. Santiago de Chile 1975-2000. Revista Diseño Urbano y Paisaje, 3(7), 1-22.

Editor: Rodrigo Firmino

Recibido: Oct. 16, 2017

Aprobado: Mayo 11, 2018 